\title{
Associations of Cutaneous Immune-Related Adverse Effects of Immunotherapy With Treatment Response in Patients With Metastatic Melanoma
}

Anagha Bangalore Kumar, MBBS ${ }^{1}$, Alan H. Bryce, $\mathrm{MD}^{2}$, Prakash Vishnu, MBBS ${ }^{3}$, Svetomir N. Markovic, MD, $\mathrm{PhD}^{1}$, Marian T. McEvoy, MD ${ }^{4}$

${ }^{1}$ Division of Medical Oncology Mayo Clinic, Rochester, MN

${ }^{2}$ Division of Hematology and Medical Oncology, Mayo Clinic Hospital, Phoenix, AZ

${ }^{3}$ Division of Hematology and Medical Oncology, Mayo Clinic, Jacksonville, FL

${ }^{4}$ Department of Dermatology, Mayo Clinic, Rochester, MN

\section{ABSTRACT}

Background: Dermatologic toxicity is the most common immune-related adverse effect of cancer immunotherapy.

Methods: We retrospectively reviewed the health records of adult ( $\geq 18$ years) melanoma patients who received ipilimumab, nivolumab, or pembrolizumab from January 1, 2011, through September 15 , 2017, at Mayo Clinic. The $x^{2}$ test was used to assess the association between development of a cutaneous immune-related adverse effect and antitumoral response to the immune checkpoint inhibitors. Odds ratios were calculated with logistic regression models and were adjusted for sex and immunotherapeutic drugs. We described the various cutaneous immune-related adverse effects and assessed the response to immunotherapy (each patient's objective clinical response was categorized as favorable [complete or partial response] or unfavorable). We then determined whether development of a cutaneous immune-related adverse effect was associated with the clinical response.

Results: Of 690 melanoma patients, 232 (33.6\%) had a cutaneous immune-related adverse effect. The most common effects were dermatitis $(21.4 \%)$, pruritus $(5.5 \%)$, and vitiligo (4.2\%). Median (range) time to onset of dermatitis was 3 (0-7) weeks; lichenoid dermatitis, 12 (6-18) weeks; and vitiligo, 40 (12-96) weeks. Development of a cutaneous immune-related adverse effect was significantly associated with favorable clinical response.

Conclusions: Development of cutaneous immune-related adverse effects is associated with favorable responses to nivolumab, ipilimumab, pembrolizumab, and ipilimumab plus nivolumab therapy in patients with metastatic melanoma.

\section{INTRODUCTION}

Immune checkpoint inhibitors (ICls), such as ipilimumab (I), pembrolizumab (P), and nivolumab $(\mathrm{N})$, have drastically improved the survival of patients with melanoma. Although these immunotherapeutic agents act by harnessing the immune response to fight melanoma, they are also associated with unique immune-related adverse effects (irAEs). Regardless of the precise mechanism involved, all irAEs occur because of excessive immune activation. 
Any organ can be affected, but cutaneous irAEs are the most common toxicities of ICls. ${ }^{1}$

Previous clinical trials and studies have reported incidence rates of $30 \%$ to $40 \%$ for cutaneous irAEs associated with I, P, and $N^{1-3}$ Studies have also shown that development of vitiligo is associated with better treatment response and prognosis of melanoma.4,5 However, sparse data describe the various cutaneous irAEs and their associations with immunotherapy in a large cohort of patients with melanoma. We sought to describe the various cutaneous irAEs, associations between these irAEs and $\mathrm{I}, \mathrm{N}$, and $\mathrm{P}$, and associations between skin reaction and antitumoral response to immunotherapy in melanoma patients.

\section{METHODS}

This study was approved by the Mayo Clinic Institutional Review Board, and informed consent was waived for this retrospective study. We conducted a retrospective review of electronic health records of adult (age $\geq 18$ years) melanoma patients who received ICI therapy with I, N, or P from January 1, 2011, through September 15, 2017, at Mayo Clinic in Rochester, Minnesota; Phoenix, Arizona; and Jacksonville, Florida. Patients were categorized into 2 groups: those who had a cutaneous irAE and those who did not. Cutaneous irAEs were graded according to the Common Terminology Criteria for Adverse Events version 4.03. ${ }^{6}$

To assess response to immunotherapy, we graded each patient's objective clinical response as favorable (ie, complete or partial response) or unfavorable. For those who did not have a cutaneous irAE while receiving any $\mathrm{ICl}$, the best response achieved while receiving immunotherapy was recorded. We excluded patients who had a concomitant second tumor $(n=5)$; received chemotherapy and immunotherapy $(n=8)$; received follow-up at other facilities, and therefore their responses could not be determined $(n=7)$; and stopped $\mathrm{ICI}$ because of intolerance $(n=6)$.

We used the $x^{2}$ test to assess the association between development of a cutaneous irAE and antitumoral clinical response to $\mathrm{ICI}$ therapy. Odds ratios (ORs) and $95 \%$ Cls were calculated with logistic regression models and were adjusted for sex and immunotherapeutic drugs. $P<.05$ was considered significant.

\section{RESULTS}

\section{Demographic Characteristics}

We identified 690 melanoma patients (486 men and 204 women) who received I $(n=228), \quad N \quad(n=16), \quad P \quad(n=297)$, or $\quad I+N$ combination therapy $(n=149)$. Of these, 232 patients $(33.6 \%)$ reported a skin reaction to immunotherapy. The median (range) age of the patient cohort was 66 (26-93) years, and the median (range) age at diagnosis of melanoma was 61 (24-91) years. Among those who had a cutaneous irAE, 155 $(66.8 \%)$ were men and $77(33.2 \%)$ were women.

The most common cutaneous irAE was grade 1 dermatitis (103 patients [14.9\%]), and other patients had vitiligo (29 [4.2\%]), lichenoid dermatitis (7 [1.0\%]), flare of preexisting psoriasis $(7 \quad[0.7 \%])$, sclerodermoid reaction $(2[0.3 \%])$, tumoral melanosis (2 [0.3\%]), and bullous pemphigoid (1 $[0.1 \%])$ (Table 1$)$.

Duration, management, and outcome of the cutaneous irAEs are summarized in Table 2. After treatment initiation, the median (range) 
Table 1. Cutaneous Immune-Related Adverse Effects due to I, $P$, and $N$ in Melanoma Patients $(N=690)$

\begin{tabular}{|c|c|c|c|c|}
\hline Diagnosis & $\begin{array}{c}\text { No. of } \\
\text { Patients (\%) }\end{array}$ & $\begin{array}{l}\text { Grade (No. of } \\
\text { Patients) }\end{array}$ & $\begin{array}{l}\text { Time to Onset, } \\
\text { Median (Range) }\end{array}$ & Site (No. of Patients) \\
\hline Any cutaneous condition & $232(33.6)$ & Not determined & $3-40 w k$ & $\begin{array}{l}\text { Self-reported maculopapular } \\
\text { rash (24) }\end{array}$ \\
\hline Dermatitis & $148(21.4)$ & $\begin{array}{l}\text { Grade } 1(103) \\
\text { Grade } 2(31) \\
\text { Grade } 3(14)\end{array}$ & $3(0-7)$ wk & $\begin{array}{l}\text { Generalized (14), torso ( } 71) \text {, } \\
\text { extremities (59), and face and } \\
\text { neck (4) }\end{array}$ \\
\hline Maculopapular rash & $145(21.0)$ & & & \\
\hline Acneiform rash & $1(0.1)$ & & & \\
\hline Urticarial plaques & $2(0.3)$ & & & \\
\hline $\begin{array}{l}\text { Pruritus without } \\
\text { dermatitis }\end{array}$ & $38(5.5)$ & $\begin{array}{l}\text { Grade } 1(32) \\
\text { Grade } 2(4) \\
\text { Grade } 3(2)\end{array}$ & $4(0-12) w k$ & $\begin{array}{l}\text { Generalized (21), torso (10), } \\
\text { extremities (4), and face (3) }\end{array}$ \\
\hline Vitiligo & $29(4.2)$ & $\begin{array}{l}\text { Grade } 1(26) \\
\text { Grade } 2(3)\end{array}$ & $40(12-96) w k^{a}$ & $\begin{array}{l}\text { Extremities (13), torso (10), face } \\
(2) \text {, and generalized (4) }\end{array}$ \\
\hline Lichenoid dermatitis $^{b}$ & $7(1.0)$ & Grade 2 (7) & $12(6-18) w k$ & $\begin{array}{l}\text { Extremities and torso (4), torso } \\
(2) \text {, and extremities (1) }\end{array}$ \\
\hline Worsening psoriasis & $5(0.7)$ & Not graded & $18(9-30) w k$ & Extremities (3) and chest (2) \\
\hline Sclerodermoid reaction ${ }^{b}$ & $2(0.3)$ & Grade 2 (2) & 15 and 39 wk & Extremities (2) \\
\hline Tumoral melanosis & $2(0.3)$ & Not determined & 40 and $56 w^{c}$ & $\begin{array}{l}\text { Chest (1) and chest and back } \\
\text { (1) }\end{array}$ \\
\hline Bullous pemphigoid & $1(0.1)$ & Grade $2(1)$ & 36 wk & Extremities (1) \\
\hline \multicolumn{5}{|c|}{$\begin{array}{l}\text { Abbreviations: I- ipilimumab; } \mathrm{N}-\text { nivolumab; } \mathrm{P}-\text { pembrolizumab. } \\
\text { a Eighteen patients had vitiligo while receiving } \mathrm{P} \text { at a median (range) of } 9(2.5-23) \text { months after treatment initiation; } 1 \text { patient, while receiving } \mathrm{P} \text { (the exact time } \\
\text { could not be determined); } 4 \text { patients, while receiving I at a median (range) of } 4(3-10) \text { months; } 3 \text { patients, while receiving I+N combination therapy at a median } \\
\text { (range) of } 11 \text { (4-11) months; } 1 \text { patient, at } 9 \text { months after starting } \mathrm{P} \text { and } 6 \text { months after starting I; } 1 \text { patient, } 17 \text { months after the first dose of } \mathrm{P} \text { and } 6 \text { months after } \\
\text { starting I+N combination therapy; and } 1 \text { patient, while receiving } \mathrm{N} \text { (the exact time could not be determined). } \\
\text { b All cases were attributed to } \mathrm{P} \text {. } \\
\text { c One patient had } 4 \text { cycles of I+N combination therapy and later continued only } \mathrm{N} \text { for } 23 \text { more cycles before melanosis was noted on the chest and back (14 } \\
\text { months after the first cycle of } \mathrm{N} \text { ); the other patient had } 4 \text { cycles of I+N combination therapy and later continued only } \mathrm{N} \text { for } 24 \text { more cycles before melanosis was } \\
\text { noted on the chest (10 months after the first cycle of } \mathrm{N} \text { ). }\end{array}$} \\
\hline
\end{tabular}


Table 2. Duration, Management, and Outcome of Cutaneous irAEs

\begin{tabular}{|c|c|c|c|}
\hline $\begin{array}{l}\text { Cutaneous irAE } \\
\text { (No. of Patients) }\end{array}$ & $\begin{array}{l}\text { Duration (No. of } \\
\text { Patients) }\end{array}$ & Management (No. of Patients) & Outcome (No. of Patients) \\
\hline $\begin{array}{l}\text { Dermatitis (148) } \\
\text { Maculopapular rash (145; } 24 \\
\text { with self-reported) } \\
\text { Urticarial plaque (2) } \\
\text { Acneiform rash (1) }\end{array}$ & $\begin{array}{l}<1 \text { wk }(20) \\
1-2 \text { wk (53) } \\
2-4 \text { wk (50) } \\
>4 \text { wk (25) }\end{array}$ & $\begin{array}{l}\text { Grade } 1 \text { and grade } 2 \text { were } \\
\text { managed with topical } \\
\text { corticosteroids, oral antihistamines } \\
\text { (23), and rarely oral } \\
\text { corticosteroids ( } 26 \text { ); grade } 3 \text { was } \\
\text { managed with higher doses of } \\
\text { corticosteroids and referral to a } \\
\text { dermatologist }\end{array}$ & $\begin{array}{l}\text { Responded to treatment (105) } \\
\text { Cleared on its own or with over-the- } \\
\text { counter medication ( } 35) \\
\text { Required ICI interruption ( } 7 \text { ) } \\
\text { Persisted at last follow-up (2) }\end{array}$ \\
\hline $\begin{array}{l}\text { Pruritus without dermatitis } \\
\text { (38) }\end{array}$ & $\begin{array}{l}<1 \text { wk }(6) \\
1-2 \text { wk }(6) \\
2-4 \text { wk }(21) \\
>4 \text { wk (5) }\end{array}$ & $\begin{array}{l}\text { Topical corticosteroids (38) } \\
\text { Antihistamines (15) } \\
\text { Systemic corticosteroids (8) }\end{array}$ & Required ICI interruption (1) \\
\hline Vitiligo (29) & $\begin{array}{l}\text { Persisted at the time } \\
\text { of last follow-up }\end{array}$ & Sun protection (29) & Persisted at the last follow-up (29) \\
\hline Lichenoid dermatitis (7) & $\begin{array}{l}2-4 \text { wk (2) } \\
>4 \text { wk (3) }\end{array}$ & $\begin{array}{l}\text { Topical corticosteroids (7) } \\
\text { Oral corticosteroids (3) }\end{array}$ & $\begin{array}{l}\text { Responded well to treatment (7) } \\
\text { Required ICI interruption (1) }\end{array}$ \\
\hline Worsening psoriasis (5) & $>4$ wk (5) & $\begin{array}{l}\text { Topical corticosteroids (5) } \\
\text { Apremilast (2) } \\
\text { Acitretin (1) }\end{array}$ & $\begin{array}{l}\text { Responded to treatment (5) } \\
\text { Required ICl interruption ( } 3^{\mathrm{a}} \text { ) }\end{array}$ \\
\hline Sclerodermoid changes (2) & $>4$ wk (2) & $\begin{array}{l}\text { Intravenous immunoglobulin, } \\
\text { mycophenolate mofetil, and oral } \\
\text { corticosteroids (1) } \\
\text { Hydroxychloroquine and oral } \\
\text { corticosteroids (1) }\end{array}$ & Required ICI interruption (2a) \\
\hline Tumoral melanosis (2) & $\begin{array}{l}\text { Persisted at last } \\
\text { follow-up }\end{array}$ & No treatment (2) & Persisted at last follow-up (2) \\
\hline Bullous pemphigoid (1) & $>4$ wk (1) & $\begin{array}{l}\text { Oral corticosteroids, } \\
\text { mycophenolate mofetil, } \\
\text { doxycycline, and topical } \\
\text { corticosteroids (1) }\end{array}$ & $\begin{array}{l}\text { Responded to treatment and } \\
\text { required } \mathrm{ICl} \text { interruption (1) }\end{array}$ \\
\hline
\end{tabular}

Abbreviations: ICl - immune checkpoint inhibitor; irAE - immune-related adverse effect.

a One of these patients required permanent discontinuation of all ICls. 
time to onset of dermatitis was $3(0-7)$ weeks; lichenoid dermatitis, 12 (6-18) weeks; and vitiligo, 40 (12-96) weeks.

\section{Histopathologic Characteristics}

Biopsy was not performed for all cutaneous irAEs. Of 14 patients who underwent skin biopsy for evaluation of dermatitis, 7 had characteristics of lichenoid dermatitis, such as vacuolar interface dermatitis with scattered dyskeratotic keratinocytes and mixed perivascular inflammation. The other 7 showed characteristics of subacute dermatitis. Results of skin biopsies confirmed the diagnoses of bullous pemphigoid, sclerodermoid reaction, lichenoid dermatitis, and tumoral melanosis.

\section{Management}

Most cutaneous irAEs were managed by medical oncologists and treated with topical corticosteroids, with or without antihistamines. Thirty-two patients (13.8\%) were referred to dermatologists. Severe cutaneous toxicity warranted hospitalization for further evaluation and aggressive management by dermatologists, in addition to permanent discontinuation of $\mathrm{ICl}$ therapy. Although $\mathrm{ICl}$ treatment was interrupted in 15 patients, at the last follow-up, only 2 patients required permanent discontinuation of all ICls. Management strategies were based on the clinical judgment of the treating physicians and the symptoms and clinical signs at presentation.

Sex did not influence the likelihood of development of a cutaneous reaction $\left(P=.94\right.$, determined with the $X^{2}$ test). Patients receiving $\mathrm{I}+\mathrm{N}$ combination therapy were more likely to have dermatitis than those receiving $\mathrm{P}(\mathrm{OR}[95 \% \mathrm{Cl}], 2.5$ [1.2$4.8] ; P=.01$ ) or $\mathrm{N}$ alone (OR [95\% Cl], 4.6 [1.0-19.9]; $P=.04)$. Development of a cutaneous irAE was significantly associated with favorable clinical response $(P<.001)$.
The objective response rate (ORR) of patients with a cutaneous irAE was markedly greater than that of those who did not have a cutaneous irAE $(67.7 \%$ vs $37.2 \%$ ) (Table 3). The ORR of those with a self-reported rash was $54.5 \%$, and that of patients with vitiligo was $86.2 \%$. Patients who had vitiligo were more likely to have a favorable response than patients without vitiligo (OR, 7.23).

Table 3. Antitumor Responses in Patients With and Without Cutaneous irAEs $\left(n=664^{a}\right)$

\begin{tabular}{|c|c|c|}
\hline Response & $\begin{array}{l}\text { Patients Without } \\
\text { Cutaneous irAEs, } \\
\text { No. (\%) }\end{array}$ & $\begin{array}{l}\text { Patients With } \\
\text { Cutaneous } \\
\text { irAEs, No. (\%) }\end{array}$ \\
\hline Favorable $^{b}$ & $178(37.2)$ & $126(67.7)$ \\
\hline Unfavorable & $300(62.8)$ & 60 (32.3) \\
\hline \multicolumn{3}{|c|}{$\begin{array}{l}\text { Abbreviation: irAE - immune-related adverse effect. } \\
\text { a We initially identified } 690 \text { melanoma patients who } \\
\text { received immune checkpoint inhibitors, but to assess } \\
\text { treatment response we excluded patients who had a } \\
\text { concomitant second tumor }(n=5) \text {, received chemotherapy } \\
\text { and immunotherapy }(n=8) \text {, received follow-up at other } \\
\text { facilities and therefore had responses that could not be } \\
\text { determined }(n=7) \text {, or stopped immune checkpoint inhibitors } \\
\text { because of intolerance }(n=6) \text {. }\end{array}$} \\
\hline
\end{tabular}

\section{DISCUSSION}

\section{Incidence}

Approximately one-third of our patients receiving $\mathrm{I}, \mathrm{N}, \mathrm{P}$, or $\mathrm{I}+\mathrm{N}$ combination therapy had a cutaneous irAE. Dermatitis (21.4\%), pruritus without a rash $(5.5 \%)$, and vitiligo $(4.2 \%)$ were most commonly associated with these agents. The most common irAE described in the health records was maculopapular rash; however, acneiform rashes and urticarial plaques were also seen.

A recent meta-analysis of dermatologic toxicity due to ICls reported a $16.7 \%$ incidence of all-grade dermatitis in patients receiving $P$ and a $14.3 \%$ incidence in those receiving N. ${ }^{7}$ Similar to the results of our study, low-grade dermatitis, pruritus, and 
vitiligo were the most common toxicities in their cohort. Another meta-analysis reported a $24.3 \%$ incidence of dermatitis in patients receiving 1.8 The likelihood of dermatitis is increased in patients receiving $\mathrm{I}+\mathrm{N}$ combination therapy. In the current study, patients receiving $\mathrm{I}+\mathrm{N}$ combination therapy were more likely to have dermatitis than those receiving $P(O R, 2.5)$ or $N$ alone $(O R$, 4.6). Hwang ${ }^{9}$ compared cutaneous toxicities in melanoma patients receiving $\mathrm{P}$ alone with those of patients receiving $\mathrm{P}+\mathrm{I}$ combination immunotherapy. In the latter group, the incidence of cutaneous irAE was greater $(88 \%)$ and the time to onset of these adverse effects was shorter.

Reports of individual cases and case series describe associations between I, P, and $\mathrm{N}$ and a wide range of cutaneous irAEs, ${ }^{10,11}$ including xerosis, ${ }^{2,12-15}$ stomatitis, ${ }^{16}$ urticaria, ${ }^{16,17}$ photosensitivity reactions, ${ }^{12}$ hyperhidrosis, ${ }^{12}$ exfoliation, ${ }^{16}$ alopecia ${ }^{2,12,17}$ and hair color changes, ${ }^{2}$ psoriasis, ${ }^{18-20}$ bullous pemphigoid, ${ }^{21,22}$ lichenoid eruptions, ${ }^{23} \quad$ lupus-like reaction, ${ }^{24}$ sclerodermoid reaction, ${ }^{25}$ panniculitis, ${ }^{26}$ erythema nodosum, ${ }^{27}$ and tumoral melanosis. ${ }^{28,29}$ Studies have also reported generalized eruptions, ${ }^{30-33}$ including drug reaction with eosinophilia and systemic symptom syndrome, ${ }^{34}$ sarcoidosis-like rash, ${ }^{35}$ lichen nitidus, ${ }^{36}$ amyloidosis, ${ }^{37}$ Sweet syndrome, ${ }^{38} \quad$ acute generalized exanthematous pustulosis, ${ }^{39}$ and vasculitis. ${ }^{40}$ Nevertheless, a particular cutaneous irAE cannot be definitively assigned to a drug on the basis of a single case report.

\section{Onset and Management of Cutaneous irAEs}

The current practice in medical oncology for the management of dermatitis is based on extent of cutaneous eruption and symptoms. ${ }^{41}$ For patients with less than $20 \%$ body surface area (BSA) involvement, symptomatic treatment includes topical corticosteroids (triamcinolone $0.1 \%$ to torso and limbs, or hydrocortisone $1 \%$ or $2.5 \%$ to face and flexures) and oral antihistamines; $20 \%$ to $50 \%$ BSA, oral corticosteroids (eg, prednisolone, $0.5-1 \mathrm{mg} / \mathrm{kg}$ ), topical therapy (similar to that used to treat $<20 \%$ BSA), and possible consultation with a dermatologist; more than 50\% BSA, oral corticosteroids (eg, prednisolone, 1-2 mg/kg) and referral to a dermatologist.

Interestingly, we noted that some cutaneous irAEs occurred acutely but some, such as vitiligo, bullous pemphigoid, and sclerodermoid reaction, occurred later in the course of treatment (ie, median time to onset ranged from 3 to 40 weeks). A recent study of 17 patients showed similar times to onset of lichenoid dermatitis and bullous pemphigoid as seen in our cohort. ${ }^{42}$ Many of our patients had grade 1 dermatitis that lasted from 1 to 2 weeks and were treated with topical corticosteroids, consistent with previous reports. Most irAEs resolve within weeks to months after initiation of immunosuppressive therapy. ${ }^{3}$ Our management strategies were in line with the recently published guidelines by the American Society of Clinical Oncology. ${ }^{43}$ These guidelines will serve as a treatment model until prospective clinical data are available.

\section{Histopathologic Characteristics}

The most common biopsy findings of maculopapular dermatitis include superficial perivascular lymphocytic dermatitis with eosinophils. ${ }^{44,45}$ Patterns resembling granulomatous, lichenoid, and spongiotic dermatitis are not uncommon. ${ }^{44}$ The inflammatory infiltrate mostly consists of $T$ lymphocytes with a predominance of CD4 ${ }^{+}$ cells over $\mathrm{CD}^{+}$cells. ${ }^{44}$ Tanaka et $\mathrm{al}^{46}$ reported an increase in interleukin 6 but not 
tumor necrosis factor $\alpha$ in their series of 6 patients with metastatic melanoma who had $\mathrm{N}$-induced psoriasis. Although previous reports have identified immune infiltrates in skin biopsy specimens from patients with irAEs, ${ }^{47}$ the specific antigens causing cutaneous irAEs have not been identified. The association of development of vitiligo with favorable antitumoral response has been linked to epitope spreading, in which immune activity against a tumor-specific antigen extends to an antigen shared by the tumor and noncancerous melanocytes. ${ }^{47}$

\section{Association of Cutaneous irAEs With Response}

Lo et $\mathrm{al}^{47}$ reviewed the association of the development of cutaneous irAEs with cancer prognosis and highlighted the significant association of vitiligo with favorable response to therapy; however, data on nonvitiligo cutaneous irAEs were insufficient. Sanlorenzo et $\mathrm{al}^{48}$ reported better cancer outcomes in patients who had a cutaneous irAE due to $P$. They analyzed data of 83 patients with various cancers who were treated with $P$ and reported that $42 \%$ of patients had cutaneous irAEs. Also, among patients who received $P$, those with a cutaneous irAE had longer progression-free survival than those without a cutaneous irAE.

In our cohort, the ORR of patients with a cutaneous irAE was markedly greater than that of those who did not. Twenty-nine $(4.2 \%)$ patients had vitiligo, and the ORR of these patients was $86.2 \%$ (25 of 29 patients). Patients with vitiligo were more likely to have a favorable antitumoral response than patients without vitiligo (OR, 7.23). Previous studies have reported a survival benefit in melanoma patients who had vitiligo attributable to immunotherapy. In a study by Hua et al, ${ }^{4}$ the ORR was $71 \%$ for 17 patients who had vitiligo. A large meta- analysis reported that melanoma patients who had vitiligo $(n=304)$ while receiving immunotherapy had better progression-free survival and overall survival than patients without vitiligo. ${ }^{5}$ The influence of lead-time bias should be considered in analyses of the association of cutaneous irAEs with favorable response to immunotherapy because patients who respond well may receive the drug for a longer duration and may have more time for long-term cutaneous irAEs to develop.

\section{Limitations}

This retrospective study was prone to ascertainment bias. Although our overall cohort was large, not all patients were evaluated by a dermatologist; most patients with cutaneous irAEs were successfully treated by oncologists. The cohort also included patients with self-reported, shortterm skin eruptions. The precise time lines of the occurrence, treatment, and outcome of the cutaneous irAEs were compiled on the basis of the clinical notes obtained with chart review. It was also challenging to classify and to ascertain the severity of each cutaneous irAE with the Common Terminology Criteria for Adverse Events grades. Objective response rate was reported instead of overall survival or progression free survival.

\section{CONCLUSION}

The cutaneous irAEs associated with immunotherapy can have diverse presentations, and physicians must understand how to recognize and to manage these various irAEs. Prospective studies would help determine the precise time to onset, course, and management of cutaneous irAEs. Emerging evidence suggests that patients with a cutaneous irAE may have a favorable response to March 2021 Volume 5 Issue 2 
immunotherapy, and further research is required to evaluate this association.

\author{
Abbreviations: \\ BSA - body surface area \\ I - ipilimumab \\ $\mathrm{ICl}$ - immune checkpoint inhibitor \\ irAE - immune-related adverse effect \\ $\mathrm{N}$ - nivolumab \\ OR - odds ratio \\ ORR - objective response rate \\ $\mathrm{P}$ - pembrolizumab
}

Author Contributions: Dr. Bangalore Kumar, Dr. McEvoy had full access to all of the data in the study and take responsibility for the integrity of the data and the accuracy of the data analysis. Study concept and design: Dr. McEvoy, Dr. Markovic, Dr. Bryce, Dr. Vishnu. Analysis and interpretation of data: Dr. Bangalore Kumar, Dr. McEvoy, Dr. Markovic. Drafting of the manuscript: Dr. Bangalore Kumar, Dr. Vishnu., Dr. Bryce, Dr. Markovic, Dr. McEvoy. Critical revision of the manuscript for important intellectual content: Dr. Bangalore Kumar, Dr. Vishnu, Dr. Bryce, Dr. Markovic, Dr. McEvoy. Statistical analysis: All authors, Mr Paul Novotny (statistician) from CCATS

\section{Conflict of Interest Disclosures: None}

Funding: This study was supported by Grant number UL1TR002377 from the National Center for Advancing Translational Sciences (NCATS). Its contents are solely the responsibility of the authors and do not necessarily represent the official views of the National Institutes of Health. A.B.K. was supported by Grant Number T32 GM008685-20 from the National Institutes of Health. The contents of this article are solely the responsibility of the authors and do not necessarily represent the official view of the National Institutes of Health.

\section{Corresponding Author:}

Marian T. McEvoy, MD

Department of Dermatology

Mayo Clinic, 200 First St SW

Rochester, MN 55905

Email: mcevoy.marian@mayo.edu

\section{References:}

1. Naidoo J, Page DB, Li BT, et al. Toxicities of the anti-PD-1 and anti-PD-L1 immune checkpoint antibodies. Ann Oncol. 2015;26(12):2375-2391.

2. Robert C, Schachter J, Long GV, et al. Pembrolizumab versus Ipilimumab in Advanced
Melanoma. N Engl J Med. 2015;372(26):25212532.

3. Weber JS, Hodi FS, Wolchok JD, et al. Safety Profile of Nivolumab Monotherapy: A Pooled Analysis of Patients With Advanced Melanoma. J Clin Oncol. 2017;35(7):785-792.

4. Hua C, Boussemart L, Mateus $C$, et al. Association of Vitiligo With Tumor Response in Patients With Metastatic Melanoma Treated With Pembrolizumab. JAMA Dermatol. 2016;152(1):45-51.

5. Teulings HE, Limpens J, Jansen SN, et al. Vitiligo-like depigmentation in patients with stage III-IV melanoma receiving immunotherapy and its association with survival: a systematic review and meta-analysis. J Clin Oncol. 2015;33(7):773-781.

6. US Department of Health and Human Services. Common Terminology Criteria for Adverse Events (CTCAE) Version 4.0. 2009. https://evs.nci.nih.gov/ftp1/CTCAE/CTCAE 4.03/ Archive/CTCAE 4.0 2009-05-

29 QuickReference 8.5x11.pdf.

7. Belum VR, Benhuri B, Postow MA, et al. Characterisation and management of dermatologic adverse events to agents targeting the PD-1 receptor. Eur J Cancer. 2016;60:12-25.

8. Minkis K, Garden BC, Wu S, Pulitzer MP, Lacouture ME. The risk of rash associated with ipilimumab in patients with cancer: a systematic review of the literature and meta-analysis. $J A m$ Acad Dermatol. 2013;69(3):e121-128.

9. Hwang S. Difference in skin toxicities observed in patients with metastatic melanoma treated with combined pembrolizumab and ipilimumab vs. pembrolizumab alone. 50th Annual Scientific Meeting of the Australasian College of Dermatologist; 2017; Sydney, Australia.

10. Curry JL, Tetzlaff MT, Nagarajan $P$, et al. Diverse types of dermatologic toxicities from immune checkpoint blockade therapy. J Cutan Pathol. 2017;44(2):158-176.

11. Collins LK, Chapman MS, Carter JB, Samie FH. Cutaneous adverse effects of the immune checkpoint inhibitors. Curr Probl Cancer. 2017;41(2):125-128.

12. Robert C, Long GV, Brady B, et al. Nivolumab in previously untreated melanoma without BRAF mutation. N Engl J Med. 2015;372(4):320-330.

13. Motzer RJ, Rini BI, McDermott DF, et al. Nivolumab for Metastatic Renal Cell Carcinoma: Results of a Randomized Phase II Trial. J Clin Oncol. 2015;33(13):1430-1437.

14. Garon EB, Rizvi NA, Hui R, et al. Pembrolizumab for the treatment of non-small-cell lung cancer. $N$ Engl J Med. 2015;372(21):2018-2028.

March 2021 Volume 5 Issue 2 
15. Robert C, Ribas A, Wolchok JD, et al. Antiprogrammed-death-receptor-1 treatment with pembrolizumab in ipilimumab-refractory advanced melanoma: a randomised dosecomparison cohort of a phase 1 trial. Lancet. 2014;384(9948):1109-1117.

16. Brahmer J, Reckamp KL, Baas $P$, et al. Nivolumab versus Docetaxel in Advanced Squamous-Cell Non-Small-Cell Lung Cancer. N Engl J Med. 2015;373(2):123-135.

17. Topalian SL, Hodi FS, Brahmer JR, et al. Safety, activity, and immune correlates of anti-PD-1 antibody in cancer. $N$ Engl $\mathrm{J}$ Med. 2012;366(26):2443-2454.

18. Troyanova-Slavkova S, Eickenscheidt L, Dumann $\mathrm{K}$, Kowalzick L. [Initially undetected de novo psoriasis triggered by nivolumab for metastatic base of the tongue carcinoma]. Hautarzt. 2018;69(8):674-680.

19. Om A, Cardon B, Cohen G. Psoriasiform eruption on the face and extremities associated with nivolumab therapy. JAAD Case Rep. 2018;4(4):373-375.

20. Bonigen J, Raynaud-Donzel C, Hureaux J, et al. Anti-PD1-induced psoriasis: a study of 21 patients. J Eur Acad Dermatol Venereol. 2017;31(5):e254-e257.

21. Lomax AJ, Ge L, Anand S, McNeil C, Lowe P. Bullous pemphigoid-like reaction in a patient with metastatic melanoma receiving pembrolizumab and previously treated with ipilimumab. Australas J Dermatol. 2016;57(4):333-335.

22. Tanita K, Fujimura T, Kambayashi Y, et al. Intensity-Modulated Radiotherapy Triggers Onset of Bullous Pemphigoid in a Patient with Advanced Melanoma Treated with Nivolumab. Case Rep Oncol. 2018;11(1):114-118.

23. Matsumoto $\mathrm{Y}$, Kadono T, Matsuoka M, et al. Disseminated erythema with intense and selective inflammation of sweat gland and lichenoid drug eruption during nivolumab therapy. J Dermatol. 2018;45(2):e33-e34.

24. Shao K, McGettigan S, Elenitsas R, Chu EY. Lupus-like cutaneous reaction following pembrolizumab: An immune-related adverse event associated with anti-PD-1 therapy. J Cutan Pathol. 2018;45(1):74-77.

25. Barbosa NS, Wetter DA, Wieland CN, Shenoy NK, Markovic SN, Thanarajasingam U. Scleroderma Induced by Pembrolizumab: A Case Series. Mayo Clin Proc. 2017;92(7):1158-1163.

26. Burillo-Martinez S, Morales-Raya C, PrietoBarrios M, Rodriguez-Peralto JL, Ortiz-Romero PL. Pembrolizumab-Induced Extensive Panniculitis and Nevus Regression: Two Novel Cutaneous Manifestations of the Post- immunotherapy Granulomatous Reactions Spectrum. JAMA Dermatol. 2017;153(7):721722.

27. Tetzlaff MT, Jazaeri AA, Torres-Cabala CA, et al. Erythema nodosum-like panniculitis mimicking disease recurrence: A novel toxicity from immune checkpoint blockade therapy-Report of 2 patients. J Cutan Pathol. 2017;44(12):1080-1086.

28. Helm MF, Bax MJ, Bogner PN, Chung CG. Metastatic melanoma with features of blue nevus and tumoral melanosis identified during pembrolizumab therapy. JAAD Case Rep. 2017;3(2):135-137.

29. Bari O, Cohen PR. Tumoral Melanosis Associated with Pembrolizumab-Treated Metastatic Melanoma. Cureus. 2017;9(2):e1026.

30. Imafuku K, Yoshino K, Ymaguchi K, Tsuboi S, Ohara K, Hata H. Nivolumab therapy before vemurafenib administration induces a severe skin rash. J Eur Acad Dermatol Venereol. 2017;31(3):e169-e171.

31. Saw S, Lee HY, Ng QS. Pembrolizumab-induced Stevens-Johnson syndrome in non-melanoma patients. Eur J Cancer. 2017;81:237-239.

32. Nayar N, Briscoe K, Fernandez Penas P. Toxic Epidermal Necrolysis-like Reaction With Severe Satellite Cell Necrosis Associated With Nivolumab in a Patient With Ipilimumab Refractory Metastatic Melanoma. J Immunother. 2016;39(3):149-152.

33. Gillis NK, Hicks JK, Bell GC, Daly AJ, Kanetsky PA, McLeod HL. Incidence and Triggers of Stevens-Johnson Syndrome and Toxic Epidermal Necrolysis in a Large Cancer Patient Cohort. $J$ Invest Dermatol. 2017;137(9):2021-2023.

34. Mirza S, Hill E, Ludlow SP, Nanjappa S. Checkpoint inhibitor-associated drug reaction with eosinophilia and systemic symptom syndrome. Melanoma Res. 2017;27(3):271-273.

35. Reule RB, North JP. Cutaneous and pulmonary sarcoidosis-like reaction associated with ipilimumab. J Am Acad Dermatol. 2013;69(5):e272-e273.

36. Cho M, Nonomura Y, Kaku Y, Dainichi T, Otsuka A, Kabashima K. Generalized Lichen Nitidus Following Anti-PD-1 Antibody Treatment. JAMA Dermatol. 2018;154(3):367-369.

37. Velasco-Tamariz V, Burillo-Martinez S, PrietoBarrios M, Calleja-Algarra A, Rodriguez-Peralto JL, Ortiz-Romero PL. Widespread biphasic amyloidosis related to ipilimumab treatment for metastatic melanoma. Int J Dermatol. 2017;56(9):e189-e191.

38. Kyllo RL, Parker MK, Rosman I, Musiek AC. Ipilimumab-associated Sweet syndrome in a

March 2021 Volume 5 Issue 2 
patient with high-risk melanoma. J Am Acad

Dermatol. 2014;70(4):e85-e86.

39. Hwang SJ, Carlos G, Wakade D, Sharma R, Fernandez-Penas P. Ipilimumab-induced acute generalized exanthematous pustulosis in a patient with metastatic melanoma. Melanoma Res. 2016;26(4):417-420.

40. Kang $A$, Yuen M, Lee DJ. Nivolumab-induced systemic vasculitis. JAAD Case Rep. 2018;4(6):606-608.

41. Kottschade L. Management of immune-related adverse events from immune checkpoint inhibitor therapy. In: Dong H, Markovic SN, eds. The Basics of Cancer Immunotherapy. Springer International Publishing; 2018:143-152.

42. Wang LL, Patel G, Chiesa-Fuxench ZC, et al. Timing of Onset of Adverse Cutaneous Reactions Associated With Programmed Cell Death Protein 1 Inhibitor Therapy. JAMA Dermatol. 2018;154(9):1057-1061.

43. Brahmer JR, Lacchetti C, Thompson JA. Management of Immune-Related Adverse Events in Patients Treated With Immune Checkpoint Inhibitor Therapy: American Society of Clinical Oncology Clinical Practice Guideline Summary. $J$ Oncol Pract. 2018;14(4):247-249.

44. Perret RE, Josselin N, Knol AC, et al. Histopathological aspects of cutaneous erythematous-papular eruptions induced by immune checkpoint inhibitors for the treatment of metastatic melanoma. Int J Dermatol. 2017;56(5):527-533.

45. Callahan MK, Postow MA, Wolchok JD. Immunomodulatory therapy for melanoma: ipilimumab and beyond. Clin Dermatol. 2013;31(2):191-199.

46. Tanaka R, Okiyama N, Okune M, et al. Serum level of interleukin- 6 is increased in nivolumabassociated psoriasiform dermatitis and tumor necrosis factor-alpha is a biomarker of nivolumab recativity. J Dermatol Sci. 2017;86(1):71-73.

47. Lo JA, Fisher DE, Flaherty KT. Prognostic Significance of Cutaneous Adverse Events Associated With Pembrolizumab Therapy. JAMA Oncol. 2015;1(9):1340-1341.

48. Sanlorenzo M, Vujic I, Daud A, et al. Pembrolizumab Cutaneous Adverse Events and Their Association With Disease Progression. JAMA Dermatol. 2015;151(11):1206-1212. 